$$
\begin{array}{r}
\text { Pontifícia Universidade Católica } \\
\text { do Rio de Janeiro }
\end{array}
$$

Jaqueline Lopes Marques

\title{
A Fazenda da Esperança do Amazonas e o olhar do ex-residente
}

\section{Dissertação de Mestrado}

Dissertação apresentada ao Programa de Pós Graduação em Serviço Social da PUC-Rio como requisito parcial para obtenção do título de Mestre em Serviço Social.

Orientadora: Profa. Ilda Lopes Rodrigues da Silva 


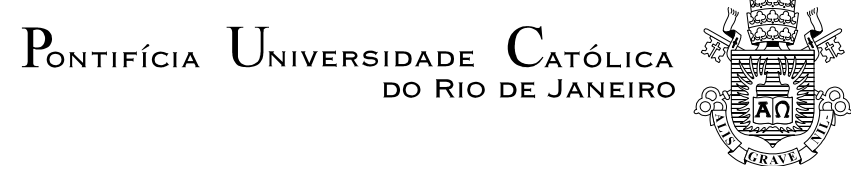

Jaqueline Lopes Marques

\section{A Fazenda da Esperança do Amazonas e o olhar do ex-residente}

Dissertação apresentada como requisito parcial para obtenção do grau de Mestre pelo Programa de PósGraduação em Serviço Social do Departamento de Serviço Social do Centro de Ciências Sociais da PUC-Rio. Aprovada pela Comissão Examinadora abaixo assinada.

Profa. Ilda Lopes Rodrigues da Silva

Orientador

Departamento de Serviço Social - PUC-Rio

Prof. Jorge Adelino Rodrigues da Silva

UFRJ

Profa. Sueli Bulhões da Silva

Departamento de Serviço Social - PUC-Rio

Profa. Mônica Herz

Vice-Decana de Pós-Graduação do

Centro de Ciências Sociais - PUC-Rio

Rio de Janeiro, 12 de maio de 2011 
Todos os direitos autorais reservados. É proibida a reprodução total ou parcial do trabalho sem autorização da universidade, da autora e da orientadora.

\section{Jaqueline Lopes Marques}

Graduou-se em Psicologia na UFAM (Universidade Federal do Amazonas) em 2004. Cursou Antropologia da Saúde na FIOCRUZ (Fundação Oswaldo Cruz) - Centro de Pesquisa Leônidas e Maria Dean - AM em 2007. Já participou de diversos congressos na área de Psicologia. Psicóloga Clínica em Fenomenologia Existencial. Coordenadora do Serviço de Plantão Psicológico na Fazenda da Esperança de Manaus. Professora de Ensino Superior no Centro Universitário do Norte UNINORTE/LAUREATE.

Ficha Catalográfica

Marques, Jaqueline Lopes

A Fazenda da Esperança do Amazonas e o olhar do ex-residente / Jaqueline Lopes Marques ; orientadora: Ilda Lopes Rodrigues da Silva. - 2011.

100 f. : il. (color.) ; $30 \mathrm{~cm}$

Dissertação (mestrado)-Pontifícia Universidade Católica do Rio de Janeiro, Departamento de Serviço Social, 2011.

Inclui bibliografia

1. Serviço social - Teses. 2. Comunidade terapêutica. 3. Álcool e outras drogas. 4. Reabilitação. 5. Fazenda da Esperança. I. Silva, Ilda Lopes Rodrigues da. II. Pontifícia Universidade Católica do Rio de Janeiro. Departamento de Serviço Social. III. Título. 
Para meus pais, Zilda e Luiz, pelo meu mais precioso bem, minha vida. Por me ensinarem a humildade, a justiça, o perdão e a reconhecer minhas próprias limitações, valores nos quais acredito e que me constroem melhor todos os dias.

Aos meus irmãos, Isabel, Jana e Luiz Junior, por me compreenderem como um exemplo, por seus olhos voltados para as minhas conquistas e por confirmarem suas presenças em meu futuro. 


\section{Agradecimentos}

A Deus, por me permitir sonhos e realizá-los; por me dar mais do que mereço.

Aos meus pais, pelo apoio, educação, confiança e credibilidade nas minhas escolhas, esse é o essencial que me basta.

Aos meus irmãos, que acreditam no meu melhor, a eles que sirvo de exemplo, à minha família e sem restrições a repetição, o essencial que me basta.

À minha orientadora Professora Ilda Lopes Rodrigues da Silva, que em sua longa experiência pessoal e profissional, não desistiu de me incentivar e acreditar que eu podia.

Ao meu amor/amigo que sempre acreditou no meu potencial e mesmo de perto ou de longe, esteve sempre presente, às vezes, sem estar ao lado, mas sempre do lado de dentro.

Aos meus amigos, nos encontros e desencontros do dia a dia, que entre um convite e outro, compreenderam minhas ausências e torceram pelo meu sucesso.

À minha avó materna, que desta sua geração é a que firme permanece. Que se orgulha muito de mim e sempre compreendeu as horas do almoço corridas e apressadas em função da docência, sempre com horários muito apertados; com ela soube do início da minha própria história e com ela tenho aprendido a sabedoria dos experientes. 
À Fazenda da Esperança e a todos aqueles que são Esperança Viva, por me permitirem experimentar esse universo que em muito contribuiu para a pessoa que venho construindo, por ser em sua expressão mais fiel, uma verdadeira comunidade, o retorno à vida. Especial destaque ao Pe. Anderson Fontes que é daquelas pessoas que mudam a nossa vida, que é um exemplo de renúncia e perseverança constantes.

Aos que conheci pelo caminho, em especial à Professora Soraya Pimenta, que em minha vida profissional, acreditou em mim, mesmo quando nem eu acreditava, pois a maior aventura em existir, é encontrar pessoas pelo caminho.

À PUC-Rio, que me acolheu em seus aconchegantes braços e me ensinou muito a cada encontro nas aulas, presenciais ou virtuais e que se estabeleceu em minhas verdades como um divisor de águas na minha caminhada acadêmica.

A todos os Professores que possibilitaram a realização deste Minter, tanto aqueles da PUC-Rio quanto aos Professores do Centro Universitário do Norte UNINORTE/Laureate, que possibilitaram o desafio de resgatar uma parte de mim que estava adormecida, mas aguardava atenta. Sem profissionais ousados na busca de novos caminhos e horizontes, este trabalho não teria se concretizado uma realidade.

A todos os funcionários da Biblioteca da Unidade X do UNINORTE, que sempre me recebiam com um "bom dia" necessário aos longos dias que construíram todos esses anos dessa conquista, com ressalvas à Alcimar Matta que sempre fora notadamente disponível em atender às muitas solicitações de leitura e empréstimos de livros, obrigada mesmo!

Aos meus colegas de trabalho, que manifestaram sua solidariedade em participar de minhas angústias de leitura, escrita e análise, foram todos muito importantes; obrigada Emili de Leon por suas indicações, obrigada Joanne Oliveira por suas contribuições.

Aos meus colegas da turma de mestrado, que compartilharam alegrias, dificuldades, inícios, fins, sorrisos, lágrimas, frustrações, conquistas; e que 
deixaram muito de si na minha caminhada. Especial destaque às amigas Ana Rosa Lago Cecílio, que está na caminhada sofrida de descobrir que é uma grande mulher, dona de um potencial ainda desconhecido por ela mesma; à Carla Dimarães, minha parceira, que se divide entre dois sonhos, o de ser mãe e mestre ao mesmo tempo, descobrindo diariamente que ambos se completam e são desafios que não suportam o espaço das palavras; e à Marsiléia Brasil, que é dona de uma alegria incomum e que me conquistou com suas divertidas sátiras sobre a condição do mestrando e a quem registro minha admiração por sua luta e persistência. Estas amigas que todos os dias compartilharam os avanços e as adversidades do processo que todas nós experimentamos nestes últimos anos, obrigada.

A todos os professores que participaram da Comissão Examinadora, emprestando seus ouvidos e tempo à escuta de minhas indicações.

A todos os amigos e familiares, que de uma maneira ou de outra, me sacudiram e acreditaram na conquista dessa árdua trajetória, meu muito obrigada. 


\section{Resumo}

Marques, Jaqueline Lopes; Silva, Ilda Lopes Rodrigues da. A Fazenda da Esperança do Amazonas e o olhar do ex-residente. Rio de Janeiro, 2011. 100p. Dissertação de Mestrado. Departamento de Serviço Social. Pontifícia Universidade Católica do Rio de Janeiro.

O estudo apresentado pretende identificar as mudanças de comportamento promovidas pela Comunidade Terapêutica Fazenda da Esperança - Centro Masculino, localizado no Amazonas, na reabilitação do uso abusivo de álcool e/ou outras drogas, o mesmo visa contribuir como referência nas discussões acerca do universo do alcoolismo e drogadição no que se refere ao processo de escolha em mudar o estilo de vida, uma vez que na atualidade em muito se observa o crescimento desenfreado do consumo e do tráfico de drogas, assumindo destaque como tema de discussão contínuo na sociedade. Para o alcance desse objetivo, fora desenvolvida escuta e análise, a fim de identificar a percepção dos exresidentes, compreendida no período de doze meses de internação, sobre o processo de reabilitação na Fazenda da Esperança; bem como identificar os principais avanços e dificuldades encontrados durante o período de reabilitação na Fazenda da Esperança e apreender as expectativas acerca da reinserção dos residentes na sociedade após a experiência na comunidade terapêutica. O delineamento da pesquisa se configura como exploratório de natureza qualitativa. As implicações derivadas do estudo apontam para resultados positivos no que tange à proposta de comunidade terapêutica, contudo, requer maior minucia de análises e produção científica nesse campo, que deve admitir-se por iniciativas de pesquisas que possam adquirir melhor conhecimento acerca da dinâmica institucional e do cenário desenhado pelo uso abusivo de álcool e outras drogas na esfera das comunidades terapêuticas.

\section{Palavras-chave}

Comunidade Terapêutica; Álcool e outras Drogas; Reabilitação;Fazenda da Esperança. 


\section{Abstract}

Marques, Jaqueline Lopes; Silva, Ilda Lopes Rodrigues da. The Esperança Farm at Amazonas state: a former residente view. Rio de Janeiro, 2011. 100p. Dissertation. Department of Social Services. Pontifícia Universidade Católica do Rio de Janeiro.

The study intends to identify the behavior changes promoted by the therapeutical community intitled Fazenda da Esperança, a male center, located in Amazonas, in the reabilitation of alcohol and/or other drugs abusive use, contributing as a cientific reference in discussions about the alcoholism and other adictions universe regarding the process of chosing to change life style, since that, nowadays, the unbridled growth of drug consunption and traffic can be highly observed, assuming the highlights in society in all its organization. To achive this goal, a process of listening and analisys were developed in order to identify the former residents perception, after they had left the community, in a twelve months residence period, about the reabilitation process in Fazenda da Esperança, identify the main progress and dificulties found during the reabilitation period in Fazenda da Esperança and verify the expectations about the residents reintegration in society after the therapeutical community experience. The research's design is exploratory and has qualitative nature. The implications founded in the study show positives results regarding the therapeuthical community proposal, however, a bigger cientific production is requierd in this field and they should begin with research initiatives that can provide better knowledge about the community's institucional dinamics and the abuse use of alcohol and other drugs scenary.

\section{Keywords}

Therapeutical Community; Alcohol and other Drugs; Reabilitation; Fazenda da Esperança. 


\section{Sumário}

Introdução

1. Álcool, outras Drogas e a Politicidade: Panorama de uma Realidade Social

1.1. Álcool, outras Drogas e a Politicidade 18

1.2. Panorama da Realidade Regional - AMAZONAS/MANAUS 28

2. Compreendendo a Instituição Fazenda da Esperança 33

2.1. Da Esquina para o Mundo 33

2.2. A Fazenda da Esperança no Amazonas 46

3. Debates Institucionais: nuances teóricas a partir de Buber, Goffman e Foucault 55

3.1. Encaminhando o Debate com Buber 55

3.2. Encaminhando o Debate com Goffman e Foucault 63

4. O Olhar do ES-residente $\quad 70$

4.1. Sobre a Residência na Comunidade 72

4.2. Sobre o Retorno à Sociedade 78

5. Considerações Finais 88

6. Referências Bibliográficas 91 


\section{Lista de Figuras}

Figura 1 - Esquina da Esperança de Ontem 33

Figura 2 - Esquina da Esperança de Hoje 33

Figura 3 - Entrada da Fazenda da Esperança - Manaus/AM 42

Figura 4 - Entrada da Fazenda da Esperança - Manaus/AM 42

Figura 5 - Identidade Visual da Fazenda da Esperança $\quad 45$

Figura 6 - Casa Emílio $\quad 47$

Figura 7 - Casa São José Operário 48

Figura 8 - Capela da Fazenda da Esperança/AM 50

Figura 9 - Casarão /Casa Central 52

Figura10 - Padaria - Fazenda da Esperança/AM 52

Figura 11 - Identidade Visual do Grupo Esperança Viva 83

Quadro 1- Grau de importância das seguintes atividades desenvolvidas na Fazenda da Esperança de Manaus 


\section{Lista de Siglas}

CT - Comunidade Terapêutica

ES - Nesse caso, sinônimo de ex, refere-se a esperança.

FE - Fazenda da Esperança

GEV - Grupo Esperança Viva 
Toda pessoa é uma ilha, no sentido muito concreto do termo; a pessoa só pode construir uma ponte para comunicar com as outras ilhas se primeiramente se dispôs a ser ela mesma e se lhe é permitido ser ela mesma. Descobri que é quando posso aceitar uma outra pessoa, o que significa especificamente aceitar os sentimentos, as atitudes e as crenças que ela tem como elementos reais e vitais que a constituem, que posso ajudá-la a tornar-se pessoa: e julgo que há nisso um grande valor. [...] quanto mais aberto estou às realidades em mim e nos outros, menos me vejo procurando, a todo custo, remediar as coisas. Quanto mais tento ouvir-me e estar atento ao que experimento no meu íntimo, quanto mais procuro ampliar essa mesma atitude de escuta para os outros, maior respeito sinto pelos complexos processos da vida.

Carl Rogers, Tornar-se Pessoa (1997) 